Original Research Article

\title{
Recent scenario on psychotropic drug usage pattern among patients attending psychiatric outpatient department of a tertiary care teaching hospital in Nepal
}

\author{
Vijay Raj Kaul ${ }^{1}$, Mirza Atif $\mathrm{Beg}^{2} *$, Shaktibala Dutta ${ }^{2}$, Shalu Bawa ${ }^{2}$, Nand Kishore Singh ${ }^{3}$, \\ Sri Hari Dutta ${ }^{4}$
}

${ }^{1}$ Department of Psychiatry, Nepal Gunj Medical College, Nepal

${ }^{2}$ Department of Pharmacology, SGRRIM and HS, Patel Nagar, Dehradun, Uttarakhand, India ${ }^{3}$ Department of Psychiatry, SGRRIM and HS, Patel Nagar, Dehradun, Uttarakhand, India

${ }^{4}$ Immunization Specialist (Supply Chain), Regional Office for South Asia, Lekhnath Marg, Kathmandu, Nepal

Received: 04 October 2016 Accepted: 03 November 2016

*Correspondence to:

Dr. Mirza Atif Beg, Email: mabeg1997@gmail.com

Copyright: () the author(s), publisher and licensee Medip Academy. This is an openaccess article distributed under the terms of the Creative Commons Attribution NonCommercial License, which permits unrestricted noncommercial use, distribution, and reproduction in any medium, provided the original work is properly cited.

\begin{abstract}
Background: Due to increasing burden of psychiatric illnesses, it is essential to study the psychotropic drug utilization pattern in actual clinical practice. The objective of the study was to study the psychotropic drug usage pattern among patients attending psychiatric OPD of a tertiary care teaching hospital in Nepal.

Methods: This observational retrospective study was conducted in Nepal Gunj Medical College, Nepal for a period of 6 months from January 2016 to June 2016. A total of 282 prescriptions from Psychiatric OPD were analysed for drug usage pattern. Prescriptions containing at least one psychotropic drug were included. Data was measured for number and percentage of prescriptions or drugs, using selected World Health Organization (WHO) drug use indicators.

Results: A total of 282 prescriptions from Psychiatric OPD were analysed. Patients had a mean age of $35.01 \pm 1.17$ years. Male and Female \%age was $41.49 \%$ and $58.51 \%$ respectively. Majority of the patients $(47.52 \%)$ were in 31 45 years age group. $70.57 \%$ patients were literate. Depression was the leading psychiatric illness seen in $144(51.06 \%)$ patients followed by Anxiety disorders which were seen in $60(21.28 \%)$ patients. A total of 2463 drugs were prescribed which included 591 (23.99\%) antipsychotic drugs followed by $462(18.76 \%)$ antidepressants, $390(15.83 \%)$ antiepileptics, $312(12.67 \%)$ supplements, 276 (11.21\%) antianxiety, $171(6.94 \%)$ antacids, 165 (6.7\%) anticholinergics, 96 $(3.9 \%)$ drugs in miscellaneous category. Drugs prescribed per prescription were 8.73 and psychotropic drugs per prescription were 6.09. Number of oral and injectable drugs were $2313(93.91 \%)$ and $150(6.09 \%)$ respectively. 87 fixed dose combinations (FDCs) of psychotropic drugs were prescribed. 903 $(36.66 \%)$ drugs were prescribed from WHO's 18th List of Essential Medicines. Conclusions: Depression was the most common psychiatric illness and antipsychotics were the most commonly prescribed medicines in psychiatry OPD. Majority of the prescriptions revealed polypharmacy.
\end{abstract}

Keywords: Drug utilization pattern, Psychotropic drugs, Polypharmacy, WHO drug use indicators

\section{INTRODUCTION}

Psychiatric disorders form an important public health priority. Of the top ten health conditions contributing to the Disability Adjusted Life Years (DALYs), four are psychiatric disorders. Psychiatric illnesses are associated with high levels of health service utilization and associated costs. ${ }^{1,2}$
The expanding and challenging field of psychopharmacology is constantly seeking new and improved psychotropic drugs to treat psychiatric disorders. $^{3}$

Psychiatrists are continuously exposed to newly introduced drugs that are claimed to be safe and more efficacious. Newer drugs are however known to be expensive and unaffordable to the majority of patients, especially in developing countries. Although 
psychotropic drugs have had a remarkable impact in psychiatry, their utilization in actual clinical practice, effectiveness and safety in the real-life situation needs continuous study. ${ }^{4-6}$

It is important to realize that inappropriate use of drugs represent a potential hazard to patients and an unnecessary expense. This necessitates a periodic review of pattern of recent scenario of drug utilization to ensure safe and effective treatment. To improve the overall drug use, especially in developing countries, international agencies like World Health Organization (WHO) and International Network for Rational Use of Drugs (INRUD) have recommended standard drug use indicators, which help us to know the shortcomings in our prescription writing. ${ }^{7}$ As there is no sufficient data on the use of psychotropic drugs in the population of Nepal, a prospective drug utilization study was conducted in psychiatry OPD of Nepal.

\section{METHODS}

This observational retrospective study was conducted in a tertiary care teaching hospital at Nepal Gunj Medical College, Nepal for a period of 6 months from January 2016 to June 2016, after the approval from the institutional ethics committee. A total of 282 prescriptions from Psychiatric OPD were analyzed for drug usage pattern using WHO drug use indicators like (1) average number of the drugs per prescription, (2) average number of the psychotropic drugs per prescription (3) percentage of injectable drugs prescribed (4) percentage of prescriptions containing psychotropic fixed dose combinations (FDCs) (5) drugs prescribed from WHO essential medicine list.

\section{Inclusion criteria}

Prescriptions of patients of both sex and all ages, suffering from a psychiatric illness and started on at least one psychotropic drug were selected. Exclusion criteria: (a) use of psychoactive substances, (b) any systemic illness, (c) lactating and pregnant women, (d) history of drug reaction. Data was entered and analyzed using Microsoft Excel 2007.

\section{RESULTS}

A total of 282 prescriptions were analyzed for drug usage pattern from Psychiatry OPD in this observational retrospective study. The number of male and female patients were $117(41.49 \%)$ and $165 \quad(58.51 \%)$ respectively. Mean age of the patients was $35.01 \pm 1.17$ years. A total of $134(47.52 \%)$ patients were seen in 3145 years, followed by $99(35.11 \%)$ patients in 16-30 years, $37(13.12 \%)$ in $46-60$ years, $7(2.48 \%)$ in more than 60 years and $5(1.77 \%)$ in $0-15$ year age group. $199(70.57 \%)$ patients were literate and $83(29.43 \%)$ patients were illiterate. Out of a total of 282 patients, 144 $(51.06 \%)$ were suffering from depression followed by 60
(21.28\%) with anxiety disorders, 42 (14.89\%) with psychotic illness, $15(5.32 \%)$ with epilepsy and 21 $(7.45 \%)$ in miscellaneous category. A total of 2463 drugs were prescribed which included 591 (23.99\%) antipsychotic drugs followed by 462 (18.76\%) antidepressants, $390 \quad(15.83 \%)$ antiepileptics, 312 (12.67\%) supplements, $276(11.21 \%)$ antianxiety, 171 (6.94\%) antacids, 165 (6.7\%) anticholinergics, 96 (3.9\%) drugs in miscellaneous category. The average drugs prescribed per prescription were 8.73 and and psychotropic drug per prescription were 6.09. A total of 87 fixed dose combinations of psychotropic drugs were prescribed which included a combination of Trifluperazine + Benzhexol in 72 prescriptions and Haloperidol + Promethazine in 15 prescriptions respectively. Number of oral and injectable drugs were $2313(93.91 \%)$ and $150(6.09 \%)$ respectively Out of a total of 2463 drugs, 903 (36.66\%) drugs were prescribed from WHO's 18thList of Essential Medicines.

Table 1: Demographic profile.

\begin{tabular}{|c|c|c|}
\hline Parameters & & Number ( $\%$ age) \\
\hline \multirow{5}{*}{$\begin{array}{l}\text { Age group } \\
\text { of the } \\
\text { patients }\end{array}$} & $0-15$ years & $5(1.77 \%)$ \\
\hline & $\begin{array}{l}16-30 \\
\text { years }\end{array}$ & $99(35.11 \%)$ \\
\hline & $\begin{array}{l}31-45 \\
\text { years }\end{array}$ & $134(47.52 \%)$ \\
\hline & $\begin{array}{l}46-60 \\
\text { years }\end{array}$ & $37(13.12 \%)$ \\
\hline & $>60$ years & $7(2.48 \%)$ \\
\hline \multicolumn{2}{|c|}{ Males:Female } & $117(41.49 \%): 165(58.51 \%)$ \\
\hline \multicolumn{2}{|c|}{ Literates: Illiterates } & $83(29.43 \%): 199(70.57 \%)$ \\
\hline
\end{tabular}

Table 2: Disease pattern.

\begin{tabular}{|ll|}
\hline Disease & Number (\% age) \\
\hline Depression & $144(51.06 \%)$ \\
\hline Anxiety & $60(21.27 \%)$ \\
\hline Psychotic illness & $42(14.89 \%)$ \\
\hline Epilepsy & $15(5.32 \%)$ \\
\hline Miscellaneous & $21(7.45 \%)$ \\
\hline
\end{tabular}

Table 3: Drug prescribing pattern.

\begin{tabular}{|ll|}
\hline Disease & Number $(\%$ age $)$ \\
\hline Antipsychotics & $591(23.99 \%)$ \\
\hline Antidepressants & $462(18.76 \%)$ \\
\hline Antiepileptics & $390(15.83 \%)$ \\
\hline Supplements & $312(12.67 \%)$ \\
\hline Antianxiety & $276(11.21 \%)$ \\
\hline Antacids & $171(6.94 \%)$ \\
\hline Anticholinergics & $165(6.7 \%)$ \\
\hline Miscellaneous & $96(3.9 \%)$ \\
\hline
\end{tabular}




\section{DISCUSSION}

In the present study the recent trends in psychotropic drug usage pattern was observed in patients attending psychiatry OPD of a tertiary care teaching hospital in Nepal. In the present study, majority of patients were seen in 31-45 year age group with a mean age of 35 years. A similar pattern was seen in previous studies. ${ }^{3,8}$ Increasing use of psychotropic drugs in this age group may be due to increased incidence of mental ill health, improved mental health literacy in general population and reduction in stigma associated with mental illness. ${ }^{9}$ In our study female patients outnumbered male patients which was similar to previous studies. ${ }^{10-13}$ This may be due to hormonal influence, effect of childbirth and differing psychosocial stress among the women. ${ }^{14}$ Depression was the leading psychiatric illness in our study which was similar to previous studies. $3,8,15$

Table 4: Other parameters.

\begin{tabular}{|ll|}
\hline Parameters & $\begin{array}{l}\text { Number (\% } \\
\text { age) }\end{array}$ \\
\hline Drugs per prescription & 8.73 \\
\hline Psychotropic drugs per prescription & 6.09 \\
\hline Oral drugs & $2313(93.91 \%)$ \\
\hline Injectable drugs & $150(6.09 \%)$ \\
\hline Fixed drug combinations (FDCs) & 87 \\
\hline Drugs from Essential Medicine List & $903(36.66 \%)$ \\
\hline
\end{tabular}

Antipsychotic drugs were the most commonly prescribed medicines followed by antidepressants. This has been seen in previous study. ${ }^{15}$ Amongst antipsychotics, atypical antipsychotics were more frequently prescribed than typical antipsychotics. Use of atypical antipsychotics has been seen in depression patients to as they have recently become a major focus for augmentation of traditional antidepressant therapy. The efficacy and safety of augmenting treatment-refractory or treatment-resistant depression with atypical antipsychotics has been well established in previous studies. ${ }^{16,17}$ They have low propensity to cause extra-pyramidal side effects, efficacy against refractory cases, better tolerance, low relapse rate, and safer adverse effect profile as compared to typical antipsychotics. ${ }^{18}$ Olanzapine was the most frequently prescribed antipsychotic in our study. Similar finding has been seen in earlier study due to the broad spectrum activity of olanzapine. ${ }^{3}$

Among the antidepressant drugs, Selective Serotonin Reuptake Inhibitors (SSRIs) were more frequently prescribed as compared to Tricyclic antidepressants (TCAs) and atypical agents. SSRIs are generally free of sedative effects, safer at higher doses and have a better tolerability, which has resulted in their growing popularity as antidepressants. ${ }^{14}$ Escitalopram was the most frequently prescribed antidepressant. This finding is similar to a previous study. ${ }^{3}$ Amongst antiepileptics, sodium valproate was the most frequently prescribed medicine to treat epileptic patients and as a mood stabilizer. This was similar to a previous study. ${ }^{8}$ Clonazepam was the most commonly prescribed Benzodiazepine (BZD) which has been seen in a previous study. ${ }^{3}$ Prescription of anticholinergics with typical antipsychotic drugs are very common, to prevent extra pyramidal side effects (EPS). ${ }^{14}$

The average number of drugs per prescription is important in psychiatry as polypharmacy and misuse of psychotherapeutic drugs is common. ${ }^{19}$ In our study the average number of drugs prescribed per prescription was 8.73 which were very high indicating polypharmacy. It was higher than the previous studies. ${ }^{3,10}$ This may lead to increased risk of drug interactions, increased hospital cost and errors of prescribing. A total of 87 FDCs of psychotropic drugs were prescribed. Most common was Trifluperazine (typical antipsychotic) + Benzhexol (central anticholinergic) which was similar to a previous study. ${ }^{3}$

Prescription of central anti-cholinergics with both typical and atypical antipsychotics is very common to prevent extra-pyramidal side-effects (EPS). The use of such FDCs can be considered as rational when used for maintenance therapy in patients who had earlier developed EPS because of antipsychotic alone; however, the routine use of such combination is irrational. ${ }^{3} 36.66 \%$ drugs were prescribed from WHO's 18th List of Essential Medicines which is comparable to a previous study. ${ }^{3}$ The primary purpose of using Essential Medicines is to promote rational use of medicines considering the three important aspects i.e. cost, safety, and efficacy. Number of oral and injectable drugs were 2313(93.91\%) and $150(6.09 \%)$ respectively which is comparable to previous studies. $^{3,20}$

Factors such as cost, adverse drug reactions and drug interactions were not evaluated during the study period.

To summarize the findings, female patients outnumbered male patients, majority of the patients were in 31-45 years age group, depression was the most common psychiatric ailment, antipsychotic drugs were the most commonly prescribed psychotropic drugs, usage of oral drugs was high, incidence of polypharmacy was seen as drugs prescribed per prescription was high and fewer drugs were prescribed from WHO's essential medicine list.

\section{CONCLUSION}

Depression was the most common psychiatric ailment and antipsychotic drugs were the most commonly prescribed psychotropic drugs in our study. Incidence of polypharmacy was seen. Our study revealed the recent trends of prescription pattern of psychotropic drugs as part of drug utilization research in a tertiary care teaching hospital at Nepal. It will provide an opportunity for 
enhancing the quality of mental healthcare for rational and judicious use of psychotropic medicines.

Funding: No funding sources

Conflict of interest: None declared

Ethical approval: Not required

\section{REFERENCES}

1. Murthy R. Mental Health Programme in the 11th five year plan. The Indian Journal of Medical Research. 2007; 125:707-12.

2. Sharma P, Das S, Deshpande S. An estimate of the monthly cost of two major mental disorders in an Indian metropolis. Indian J Psychiatry. 2006;48:14348.

3. Rode SB, Rajesh KA, Harsh VS, Umesh S. A study on drug prescribing pattern in psychiatry out-patient department from a tertiary care teaching hospital. Int J Basic Clin Pharmacol. 2014;3(3):517-22.

4. Costa J, Rosa MM, Ferreira JJ, Sampaio C, Vaz Carneiro A. Cardiac effects of acute poisoning with tricyclic antidepressants: systematic review of the literature. Part I. Rev Port Cardiol. 2001;20(6):67178.

5. Moore S, Jaime LK, Maharajh H, Ramtahal I, Reid S, Ramsewak FS, et al. The prescribing of psychotropic drugs in mental health services in Trinidad. Rev Panam Salud Publica. 2002;12(3):207-14.

6. Davidson JR, Feltner DE, Dugar A. Management of generalized anxiety disorder in primary care: identifying the challenges and unmet needs. Prim Care Companion J Clin Psychiatry. 2010;12(2).

7. WHO. Drugs and Therapeutics Committees - A Practical Guide. Geneva: World Health Organization; 2003.

8. Dutta SB, Beg MA, Kaul V, Dutta S, Dhasmana DC. Psychotropic drug utilization study in Psychiatric OPD of a Tertiary care teaching hospital in Dehradun, Uttarakhand. Journal of Advance Researches in Biological Sciences. 2013;5(4):386-91.

9. Jorm A, Christensen H, Griffiths K. Changes in depression awareness and attitudes in Australia: the impact of beyond blue: the national depression initiative. Australian and New Zealand. Journal of Psychiatry. 2006;40:42-6.

10. Thakkar et al. A Drug Utilization Study of Psychotropic Drugs Prescribed in the Psychiatry Outpatient Department of a Tertiary Care Hospital. Journal of Clinical and Diagnostic Research. 2013;7(12):2759-64.

11. Patel V. Gender in Mental Health Research. Department of Gender, Women and Health Family and Community Health. World Health Organization. 2005.

12. Mohammed P, Mohamed E, Rajan S, Kumar K. Gender and mental health in Kerala Institute of Social Studies Trust. 2002.

13. Earls F. Sex differences in psychiatric disorders: origins and developmental influences. Psychiatric developments. 1987;5(1):1-23.

14. Piparva KG, Parmar DM, Singh AP, Gajera MV, Trivedi HR. Indian J Psychol Med. 2011;33(1):54-8.

15. Ahmed T, Sharma S, Ali S, Sachdev D, Sharma R, Jaiswal M. Drug utilization pattern in psychiatry outdoor patients at tertiary care teaching hospital of Bastar region. IJPR. 2015;5(4):98-103.

16. Wright BM, Eiland EH 3rd, Lorenz R. Augmentation with atypical antipsychotics for depression: a review of evidence-based support from the medical literature. Pharmacotherapy. 2013;33(3):344-59.

17. Komossa K, Depping AM, Gaudchau A, Kissling W, Leucht S. Second-generation antipsychotics for major depressive disorder and dysthymia. Cochrane Database Syst Rev. 2010; 8(12):CD008121.

18. Dhasmana DC, Rawat Y, Mishra KC. What is so atypical about atypical antipsychotic? Indian J Pharmacol. 2003;35:322-4.

19. Avanthi E, Somashekar HE, Kumar P, Sushma HK, Sudarshan CY et al. Prescribing pattern of antidepressants in psychiatric unit of a tertiary care hospital. Int J Basic Clin Pharmacol. 2014;3(4):66770.

20. Dutta SB, Dhasmana DC, Bhardwaj R. Psychotropic Drug Utilization Pattern among Schizophrenics. Indian J Psychiatry. 2004;46(4):381-2.

Cite this article as: Kaul VR, Beg MA, Dutta S, Bawa S, Singh NK, Dutta SH. Recent scenario on psychotropic drug usage pattern among patients attending psychiatric outpatient department of a tertiary care teaching hospital in Nepal. Int J Basic Clin Pharmacol 2016;5:2649-52. 